\title{
ARENARIA CERASTIOIDES POIRET EN ESPAÑA
}

\author{
M. J. GALLEGO
}

RESUMEN: Se cita la presencia de Arenaria cerastioides Poiret en el Sur de España, incluyendo descripción y comentario de sus caracteres diferenciales con Arenaria hispanica Sprengel.

SUMMARY: Arenaria cerastioides Poiret is recorded from South Spain. Description, commentary and differencial characters from Arenaria hispanica Sprengel are included.

En una nota anterior (Gallego, 1982: 6) se discute la identidad de Arenaria spathulata auct. hisp. (= A. hispanica Sprengel) sobre material de la Península Ibérica.

Al estudiar material de este género de distintos herbarios, se ha encontrado en el herbario de Ginebra (G) un pliego procedente del Sur de España, que por sus caracteres se identifica con la verdadera A. cerastioides Poiret.

Arenaria cerastioides Poiret, Voy. Barb. 2: 166 (1789)

A. spathulata Desf., Fl. Atl. 1: 358 (1798)

Anual, glandular-pubescente, víscida en la inflorescencia. Tallo hasta $20 \mathrm{~cm}$, ascendente, ramificado. Hojas hasta $15 \mathrm{~mm}$, de espatuladas u oblanceoladas a linear-lanceoladas; las inferiores pecioladas, obtusas, las medias y superiores sentadas, subobtusas o más o menos agudas. Pedicelos hasta $18 \mathrm{~mm}$. Cáliz con indumento básicamente glandular. Sépalos 3,5-4 mm, con más de 3 nervios, el central más pronunciado que los laterales; los externos oblongo-lanceolados a lanceolados, obtusos o subobtusos, herbáceos sin margen escarioso o con él muy estrecho; los internos oblongos, obtusos, con amplio margen escarioso. Pétalos 5-6 mm, redondeados o emarginados en el ápice blancos. Anteras 0,6-7 mm, oblongas, violetas. Cáṕsula 4-4,5 mm, igualando o sobrepasando ligeramente el cáliz. ob̉longa, ensanchada en la base, con dientes retrorsos, membranosa. Semillas 0,4-0,5 mm, reniformes con caras planas o débilmente cóncavas y dorso levemente hundido, tuberculadas y negras. 
Ecologia: Arenas litorales.

Localidad: Málaga ("Granada"), Torrox, VI.1909, Domingo (G).

Esta especie ha sido frecuentemente confundida con Arenaria hispanica Sprengel. Esta última es más robusta, con sépalos generalmente de 4-5,5 mm, oblongos o ligeramente pandurados, pétalos $(4,8-)$ 6,5-9 (-11) $\mathrm{mm}$, anteras 0,7-1 $(-1,3) \mathrm{mm}$. Cápsula 4-5,5 $(-6) \mathrm{mm}$, con dientes erectos, $1 / 2-1 / 3$ del tamaño de la cápsula. Sus semillas son globosas o subglobosas no tuberculadas, pudiendo presentar sobre su superficie papilas muy variables en número y tamaño. Por sus caracteres se piensa que A. cerastioides está relacionada con el grupo de Arenaria retusa, diferenciándose claramente, entre otros caracteres, por sus sépalos obtusos y no agudos.

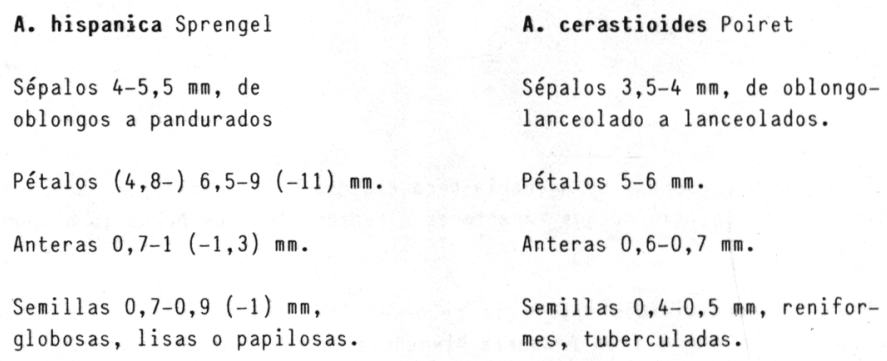

A. hispanica Sprengel

Sépalos 4-5,5 $\mathrm{mm}$, de

oblongos a pandurados

Pétalos $(4,8-) 6,5-9(-11) \mathrm{mm}$.

Anteras $0,7-1(-1,3) \mathrm{mm}$.

Semillas $0,7-0,9(-1) \mathrm{mm}$,

globosas, lisas o papilosas.

\author{
A. cerastioides Poiret \\ Sépalos 3,5-4 mm, de oblongo- \\ lanceolado a lanceolados. \\ Pétalos 5-6 mm. \\ Anteras $0,6-0,7 \mathrm{~mm}$. \\ Semillas $0,4-0,5 \mathrm{~mm}$, renifor-
}

mes, tuberculadas.

BIBLIOGRAFIA

GALLEGO, M.J. - 1982 - in B. VALDES, S. TALAVERA \& al. (eds.). Herbarium Universitatis Hispalensis. Flora Selecta. Centuria I. Sevilla. 